\title{
Triple-Blind, Prospective, Internally Controlled Comparative Study Between AbobotulinumtoxinA and OnabotulinumtoxinA for the Treatment of Facial Rhytids
}

\author{
Ramtin Kassir • Aparanjita Kolluru • Martin Kassir
}

To view enhanced content go to www.dermtherapy-open.com Received: June 17, 2013 / Published online: August 16, 2013

(C) The Author(s) 2013. This article is published with open access at Springerlink.com

\section{ABSTRACT}

Introduction: OnabotulinumtoxinA (ONA; Botox, Allergan, Irvine, CA) was discovered for cosmetic use in the mid-1980s for which it was FDA approved in April 2002. AbobotulinumtoxinA (ABO; Dysport, Valeant Pharmaceuticals International, Inc, Montreal, Quebec) was FDA approved in April 2009 for therapeutic and esthetic uses. The most recent studies make a comparison between the two formulations; however, information is still

R. Kassir $(\bowtie)$

Park Avenue Plastic Surgery and Dermatology, 799 Park Avenue, New York, NY 10021, USA e-mail: drkassir@drkassir.com

A. Kolluru

Richmond Program, New York Medical College,

New York, NY 10310, USA

M. Kassir

Mona Lisa Dermatology, 8335 Walnut Hill Ln, Dallas, TX 75231, USA

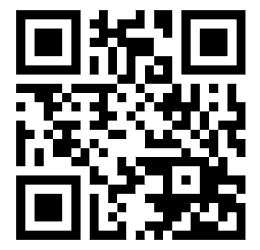

Enhanced content for this article is available on the journal web site: www.dermtherapy-open.com lacking in comparison studies. In this study, we compare efficacy and safety of a single treatment of two preparations of botulinum toxin A in patients with moderate to severe rhytids in the glabellar and crow's feet areas.

Methods: A total of 85 patients with moderate to severe wrinkles in either the glabellar or crow's feet area, or both, were given a single injection on day 0 , with $\mathrm{ABO}$ and ONA injected on opposite sides of the face. Follow-up assessments were done at 2 weeks, 1 month, 3 months, 4 months, and 5 months. The study end points were onset of action, change in degree of wrinkles, patient satisfaction, duration of effect, and adverse effects.

Results: Results of onset of improvement with $\mathrm{ABO}$ vs. ONA in the glabellar and crow's feet regions show higher percentage of patients with earlier onset improvement with $\mathrm{ABO}$. Evaluator assessment showed $\mathrm{ABO}$ lasted longer after 3 months in a significant number of patients in both areas, $83 \%$ with $\mathrm{ABO}$ vs. $48 \%$ with $\mathrm{ONA}$ at 4 months in the glabellar area, and $65 \%$ with $\mathrm{ABO}$ vs. $47 \%$ with $\mathrm{ONA}$ at 4 months in the crow's feet area.

Conclusion: Time to improvement showed earlier onset and longer duration of improvement in a higher percentage of 
individuals with $\mathrm{ABO}$ when compared with ONA. ABO provides a safe and effective alternative in a dose ratio of 2.5:1 and 3:1 in the glabellar and crow's feet area, respectively.

Keywords: Botox; Botulinum toxin; Crow's feet; Dermatology; Dysport; Facial rhytids; Glabella

\section{INTRODUCTION}

OnabotulinumtoxinA (ONA) has been used since the early 1980s for reducing muscle spasms in medical illnesses [1]. Over the past 20 years, ONA has been recognized by regulatory authorities in approximately 80 countries worldwide as an effective treatment for 21 different medical uses including strabismus, blepharospasm, cervical dystonia, and severe primary axillary hyperhidrosis. Its use as a cosmetic agent was recognized in the mid-1980s and after a decade of 'off-label' use, efficacy and tolerability in the treatment of glabellar frown lines was demonstrated in two large, multicenter, randomized, double-blind placebo-controlled trials, known as Glabellar Lines I and II studies [1]. These trials led to FDA approval, in April 2002, of ONA for the temporary reduction of moderate to severe glabellar lines due to muscular hypertrophy at a dose of 20 units (U) for adults aged $\leq 65$ years [2].

AbobotulinumtoxinA (ABO), another formulation of botulinum toxin $\mathrm{A}$, has been used worldwide since 1990 and is approved in 76 countries for therapeutic use. It was first approved for esthetic use outside the United States in 2001 and is currently marketed in 27 countries for esthetic use before being studied for use in glabellar lines in the US. After a series of trials, $\mathrm{ABO}$ was approved for the treatment of glabellar lines by the FDA in April of 2009 [3].
The derivation of ONA and $\mathrm{ABO}$ from botulinum toxin $\mathrm{A}$ is responsible for similar effects on the musculature. Both agents act by inhibiting the calcium-mediated release of acetylcholine from the nerve ending, causing temporary muscle paralysis. The weight of the core neurotoxin is the same at $150 \mathrm{kDa}$ with both agents; however, they differ in molecular weight of the botulinum toxin/hemagglutinin complex. ONA is a $925-\mathrm{kDa}$ protein and $\mathrm{ABO}$ has been reported as a $400-600 \mathrm{kDa}$ protein, but the specific weight has not been disclosed by the manufacturer (Ipsen Ltd, United Kingdom) $[4,5]$. Differences in the molecular weight of the protein complex have been reported to theoretically cause $\mathrm{ABO}$ to migrate more than ONA, with a possibility that there would be a greater incidence of eyelid/eyebrow ptosis with $\mathrm{ABO}$ when injected supraorbitally in the corrugators, though this effect has not been reported in the trials [6].

Slight differences in the properties of $\mathrm{ABO}$ and ONA may result in differences in efficacy. It is the opinion of many physicians, along with feedback from their patients, that $\mathrm{ABO}$ has a slightly greater efficacy (earlier onset and longer duration of effect) than ONA, though this information is largely anecdotal [7]. There have been several reports on the efficacy and safety of ONA and $\mathrm{ABO}$, yet the literature contains few studies comparing these two drugs [7-12]. Additionally, comparative studies are lacking evaluating treatment in facial wrinkles other than in the frown region. A difference in efficacies might suggest that one agent is a more suitable option for patients and clinicians seeking to prolong treatment intervals yet maintain a continuous effect of reduced wrinkle appearance.

In this prospective clinical study, we report the results of a comparison of efficacy parameters, particularly onset and duration, 
and the safety of ONA and $\mathrm{ABO}$ in the treatment of rhytids in the glabellar and crow's feet areas.

\section{METHODS}

This was a prospective, comparative, tripleblinded, single-center, randomized, internally controlled clinical trial.

\section{Subject Population}

A four-point grading scale was used to evaluate wrinkle severity at maximum contraction in the glabellar and crow's feet areas: $0=$ no wrinkles, $1=$ mild wrinkles, $2=$ moderate wrinkles, $3=$ severe wrinkles [13-15] (Fig. 1). Only patients with grade 2 or 3 , corresponding to moderate to severe wrinkles at maximum contraction, were eligible to enroll in the study. Patients had to be aged 18-65 years to be included. Patients were excluded if they had any of the following: pregnancy, treatment with $\mathrm{ABO}$ or ONA in the preceding 9 months, surgery around the eye, facial scars that would interfere with assessment of wrinkles, thick sebaceous skin, dermatochalasis, neuromuscular disorders such as myasthenia gravis or multiple sclerosis, use of aminoglycoside or curare-like agents, history of facial nerve palsy, and psychiatric illnesses that would interfere with subject assessment of wrinkles.

\section{Randomization and Masking}

Patients were randomized into one of two groups using a computer-generated randomization list. The two groups were: (1) $\mathrm{ABO}$ injection on the right side of the face and ONA on the left; and (2) ONA injection on the right side of the face and $\mathrm{ABO}$ on the left. This allowed each patient to act as their own control, thereby limiting variability from patient to patient (i.e., muscle mass). The physician was the injector as well as an evaluator. The physician, second evaluator, and patient were blinded to the treatment.

Block randomization was prepared in groups of six. A medical assistant kept the randomization list and was the only person who knew which side which treatment was being given. The patient number and treatment were determined at baseline visit. Prior to treatment syringes were placed in the treatment room with instructions for the area and side for the treatment to be injected.

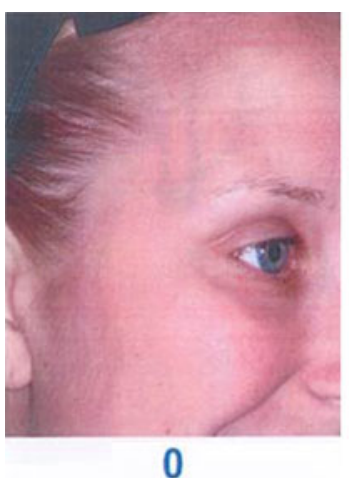

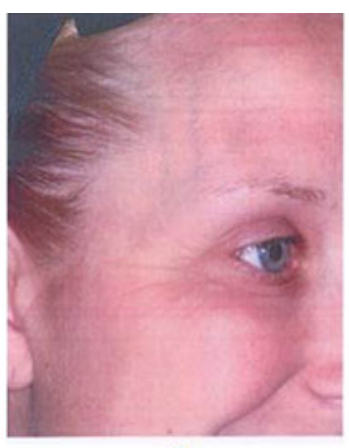

1

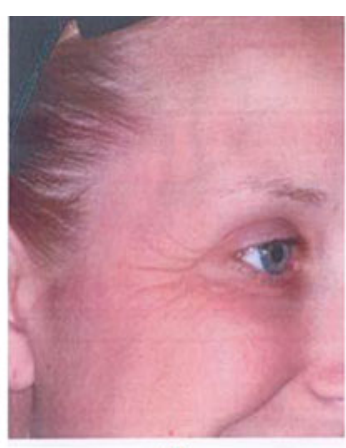

2

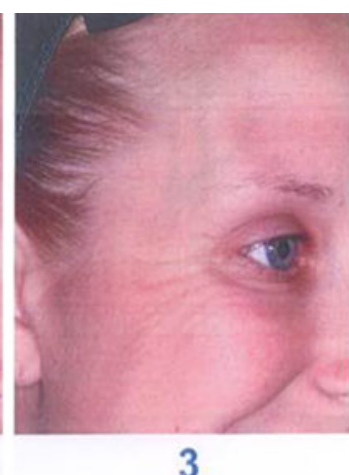

3

Fig. 1 The four-point grading scale used to evaluate wrinkle severity at maximum contraction in the glabellar and crow's feet areas: $0=$ no wrinkles, $1=$ mild wrinkles, $2=$ moderate wrinkles, $3=$ severe wrinkles $[13-15]$ 


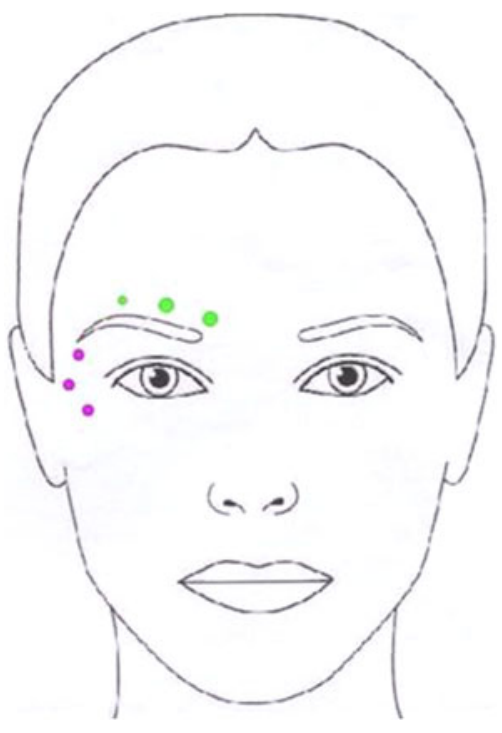

Fig. 2 Unilateral injecting points for the glabellar and crow's feet areas

\section{Treatment Regimen}

The physician prepared $\mathrm{ONA}$ and $\mathrm{ABO}$ in separate $0.3-\mathrm{ml}$ insulin syringes and reconstituted each with $0.9 \%$ preservative-free saline. $\mathrm{ABO}$ was diluted in $3 \mathrm{ml}$ of saline to make concentrations of $20 \mathrm{U}$ for the glabellar area and $30 \mathrm{U}$ for the crow's feet area. ONA was diluted in $2.5 \mathrm{ml}$ of saline to make a concentration of $8 \mathrm{U}$ for the glabellar area and in $3 \mathrm{ml}$ of saline to make a concentration of $10 \mathrm{U}$ for the crow's feet area. Syringes for the glabellar area were prepared to a final volume of $0.2 \mathrm{ml}$ and syringes for the crow's feet area were prepared to a final volume of $0.3 \mathrm{ml}$ so that syringes for each area would look identical in order to make the treatment unknown to the injector.

The doses were standard for unilateral areas at $20 \mathrm{U} \mathrm{ABO}$ and $8 \mathrm{U}$ ONA for the glabellar area, and $30 \mathrm{U} \mathrm{ABO}$ and $10 \mathrm{U}$ ONA for the crow's feet area. Each patient received treatment in the frown and/or crow's feet area(s) based on the degree of wrinkles (moderate to severe). Figure 2 shows the injecting points for the glabellar and crow's feet areas. A total of three injecting points were performed in the glabellar area unilaterally and all were injected into the corrugator supercilii muscle. A total of three injections were given in the unilateral crow's feet area: tail of the brow, lateral canthus, and inferolateral from the lateral canthus. All were $1-1.5 \mathrm{~cm}$ from the lateral canthus. Volume in the syringe was distributed in the three sites of the glabellar area unilaterally at a percentage from medial to lateral at 40\%/40\%/20\%, and evenly distributed in the three sites in the crow's feet area.

\section{Study Parameters}

The parameters used to compare ONA and $\mathrm{ABO}$ included time to improvement of wrinkles, improvement in the grading of wrinkles based on a four-point scale at specific time points, patient satisfaction, and duration of activity by complete return of muscle activity. Time to improvement was also recorded by patients. Duration of improvement, indicated by complete return of muscle activity, was assessed by the evaluator at the follow-up visit. Response was defined as an improvement of at least one grade at maximal contraction based on evaluator assessment. Duration of effect was defined as the complete return of muscle activity and was assessed by patients and the evaluator. Patient satisfaction was recorded by the subject on a diary card at each follow-up visit, and was measured based on patients' own feeling of improvement in appearance of wrinkles using a scale from 1 to 5 , where $1=$ minimally satisfied and $5=$ extremely satisfied.

Safety and efficacy evaluations for wrinkle severity at maximum contraction were conducted at the baseline visit, and at follow- 
up visits at 2 weeks, 1 month, 3 months, 4 months and 5 months. Patients were informed of the possible side effects and were told to call or return immediately if any of the following occurred: neck pain, difficulty swallowing, shortness of breath, nausea, weakness, double vision, trouble breathing, talking, or swallowing, hoarse voice, crusting or drainage from the eyes, severe skin rash or itching, fast, slow, or uneven heartbeats, general ill feeling, fever, cough, sore throat, runny nose, flu symptoms, dry mouth, dry eyes, increased sweating in areas other than the underarms, itchy or watery eyes, or increased sensitivity to light.

All procedures followed were in accordance with the ethical standards of the responsible committee on human experimentation (institutional and national) and with the Helsinki Declaration of 1975, as revised in 2000 and 2008. Informed consent was obtained from all patients for being included in the study.

\section{Statistical Analysis}

Due to the paired nature of the data, the Wilcoxon signed rank test was used to compare differences in onset time and duration of ONA and ABO. The Wilcoxon signed rank test is a non-parametric version of a paired samples $t$ test. Analysis was done using SAS software Version 9.2 of SAS Institute Inc., Cary, NC.

The study was Institutional Review Board approved and was conducted in a private practice.

\section{RESULTS}

Ninety-three patients were treated with $\mathrm{ABO}$ and ONA over a period of 2 months ( 87 women and 6 men). Most patients were Caucasian with an average age of 47 years. Thirty-six patients received treatment with $\mathrm{ONA}$ and $\mathrm{ABO}$ in two areas (glabella and crow's feet areas). Fifty-seven patients received treatment with $\mathrm{ABO}$ and ONA in one area (either glabella or crow's feet areas). Eight patients did not continue follow-up visits and were removed from the study, leaving 35 patients treated in 2 areas and 50 patients treated in 1 area, for a total of 59 patients treated in the glabellar area and 61 patients treated in the crow's feet area. No patients discontinued visits due to adverse effects from the treatment.

\section{Time to Onset}

All patients had onset of improvement in the glabellar area within 5 days when using $\mathrm{ABO}$ and ONA, with $28 \%$ reporting improvement within one day with $\mathrm{ABO}$ and $17 \%$ with ONA, $59 \%$ by the second day with $\mathrm{ABO}$ vs. $37 \%$ with ONA, $85 \%$ by the third day with $\mathrm{ABO}$ vs. $70 \%$ with ONA, $89 \%$ by the fourth day with $\mathrm{ABO}$ vs. $87 \%$ with ONA, and $100 \%$ by the fifth day with both treatments (Fig. 3a). Time to onset was significantly quicker with $\mathrm{ABO}$ than ONA, with a mean difference of 0.52 days $(P<0.0001)$.

In patients injected with $\mathrm{ABO}$ in the crow's feet area, 19\% reported onset by the first day, $54 \%$ by the second day, $80 \%$ by the third day, $90 \%$ by the fourth day, and $100 \%$ by the third day (Fig. 3b). In patients injected with ONA in the crow's feet area, 13\% responded within the first day, $39 \%$ by the second day, $68 \%$ by the third day, $88 \%$ by the fourth day, and $100 \%$ by the fifth day (Fig. 3b). As with the glabellar region, time to onset was significantly quicker with $\mathrm{ABO}$ than ONA, with a mean difference of 0.33 days $(P=0.0025)$. 

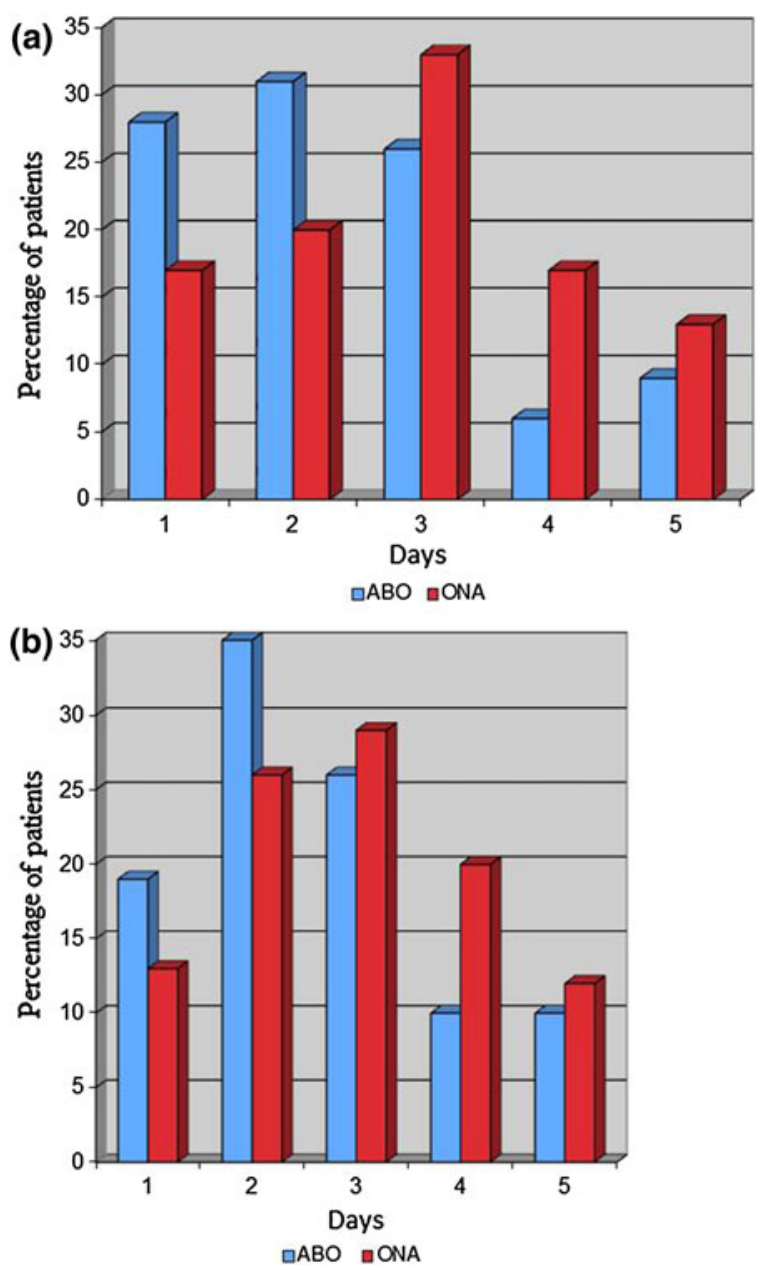

Fig. 3 Percentage of patients who had onset of action for $\mathrm{ABO}$ and ONA within the first day, by the second day, third day, fourth day, and fifth day in a the glabellar region and $\mathbf{b}$ the crow's feet region

\section{Duration of Treatment/Response Rate}

In the glabellar region, the response rate was equivalent for ONA and $\mathrm{ABO}$ at 2 weeks (100\%), 1 month (98\%), and 3 months (98\%) (Fig. 4a). The response rate was higher with $\mathrm{ABO}$ at 4 months ( $83 \%$ vs. $48 \%$ with ONA) and at 5 months $(27 \%$ vs. $2 \%$ with ONA), with significant mean difference in duration of 2.5 weeks $(P<0.0001)$.

The early response rate in the crow's feet region was equivalent for $\mathrm{ONA}$ and $\mathrm{ABO}$ with $100 \%$ of patients responding at 2 weeks and
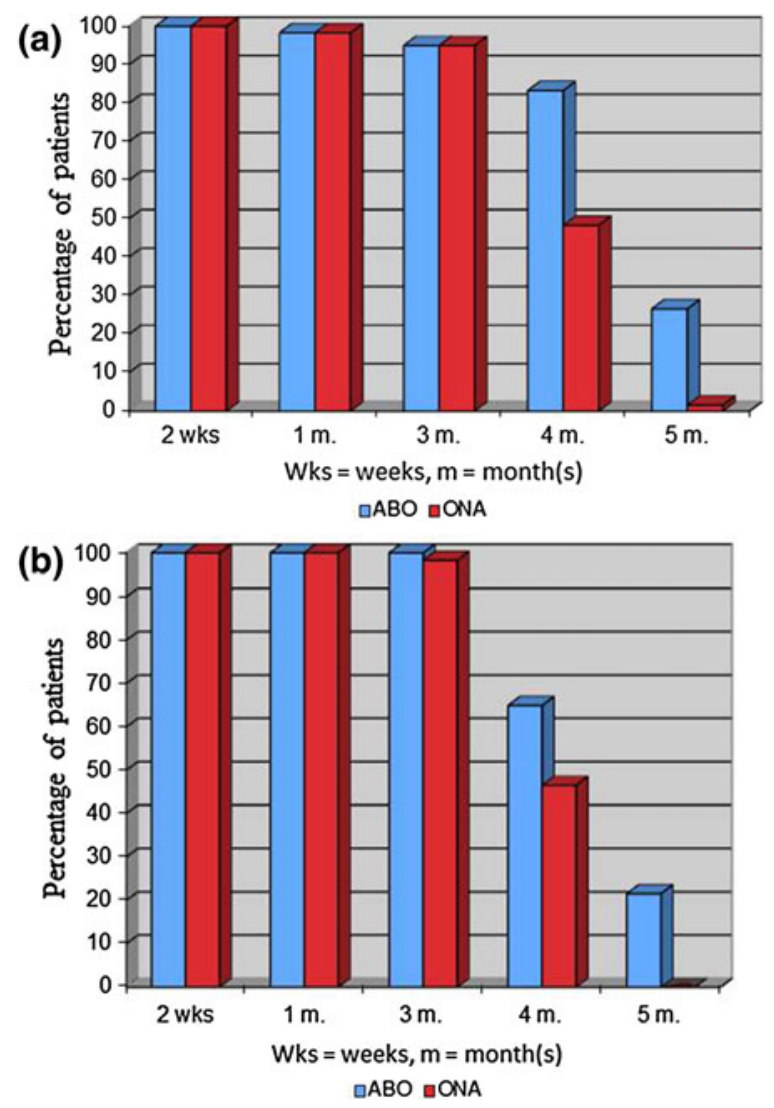

Fig. 4 Response rate for $\mathrm{ABO}$ and $\mathrm{ONA}$ at specific time points in a the glabellar region and $\mathbf{b}$ the crow's feet region

1 month and a similar rate observed at 3 months (100\% with ABO vs. $98 \%$ with ONA) (Fig. 4b). The response rate was higher with $\mathrm{ABO}$ at 4 months (65\% vs. $47 \%$ with ONA) and at 5 months (22\% vs. $0 \%$ with ONA), with significant mean difference in duration of 1.6 weeks $(P<0.0001)$.

\section{Evaluator Assessment}

For patients at 2 weeks, 1 month, and 3 months, blinded evaluators reported that a greater proportion of patients had fewer wrinkles on the side where $\mathrm{ABO}$ was injected than the side with ONA for both the glabellar and crow's feet areas (Fig. 5a, b). At 4 months, equal numbers of patients had less wrinkles on the side with ONA 

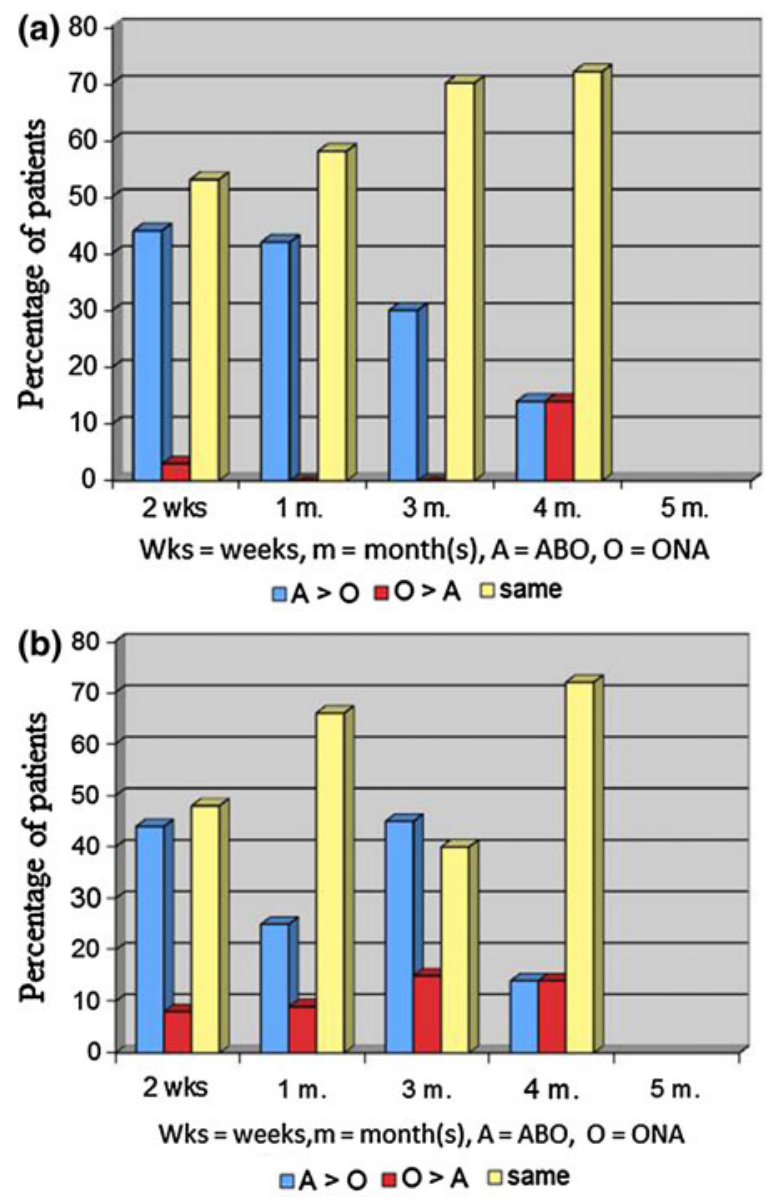

Fig. 5 Evaluator assessment for wrinkle severity in a the glabellar region and $\mathbf{b}$ the crow's feet region. $\mathrm{A}>\mathrm{O}=$ side with $\mathrm{ABO}$ had less wrinkles than side with ONA. $\mathrm{O}>\mathrm{A}=$ side with ONA had less wrinkles than side with $\mathrm{ABO}$. Same $=$ degree of wrinkles on both sides were the same

vs. $\mathrm{ABO}$ and $\mathrm{ABO}$ vs. ONA. This was seen for both the glabellar and crow's feet areas. In a large number of patients, no difference was noted between the two sides at each specific time point.

\section{Patient Satisfaction}

Patient satisfaction showed that a larger percentage of patients were more satisfied with $\mathrm{ABO}$ than ONA at 2 weeks and 1 month (Fig. 6a, b). Additionally, there is an increasing rating of satisfaction from 2 weeks to 1 month with both
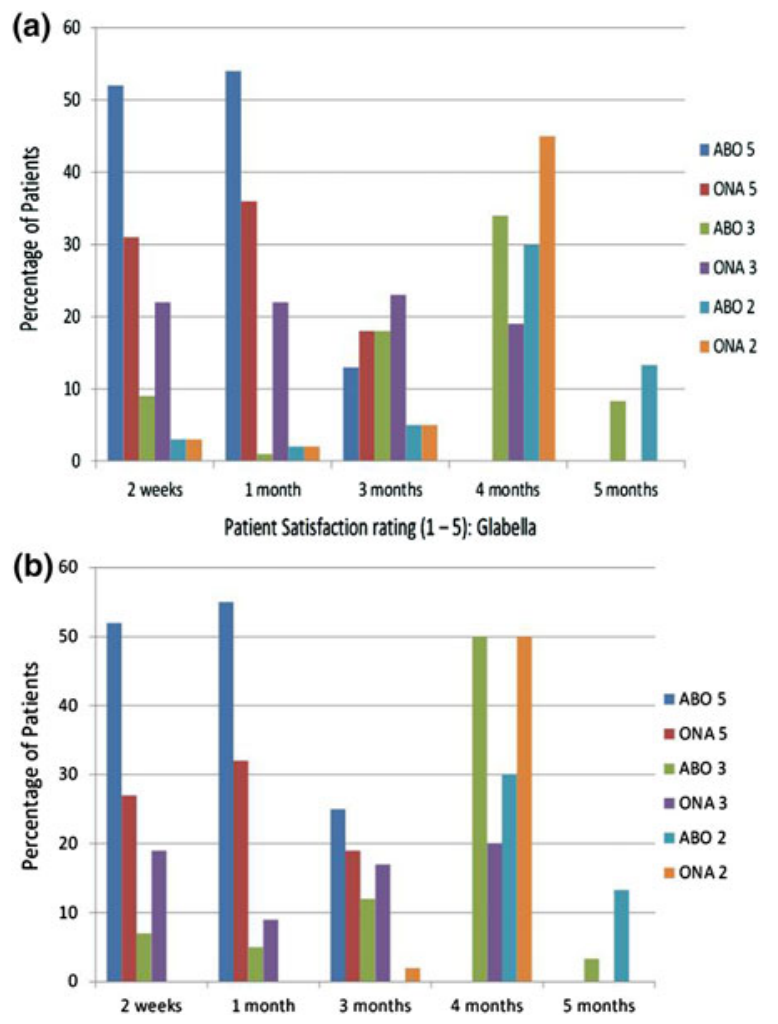

Fig. 6 Patient satisfaction for $\mathrm{ABO}$ and ONA using a rating scale from 1 to 5 at specific time points in a the glabellar region and $\mathbf{b}$ the crow's feet region

$\mathrm{ABO}$ and $\mathrm{ONA}$, indicating a peak effect of both treatments during this time. Five patients gave a rating of 3, and 8 patients gave a rating of 2 for $\mathrm{ABO}$ in the glabellar region at 5 months reporting that they felt there was still a slight effect of $\mathrm{ABO}$ at 5 months. Two patients gave a rating of 3 , and 8 patients gave a rating of 2 for $\mathrm{ABO}$ in the crow's feet area at 5 months reporting that there was still a slight effect of $\mathrm{ABO}$ at 5 months (Fig. 6b). No patients reported activity for ONA at 5 months in the glabellar or crow's feet region.

\section{Safety}

Three patients experienced headaches after injection, which resolved after a week and may have been unrelated to the injection. One 
patient had slight bruising and this also resolved within one week. Throughout the course of the study, one patient developed brow ptosis with $\mathrm{ABO}$ as seen by patient and evaluator assessment.

\section{DISCUSSION}

Differences were observed in the time to onset of improvement of wrinkles between the two sides/agents, such that a larger number of patients had a quicker onset of action with $\mathrm{ABO}$ than with ONA. After 3 months, ABO was active for a larger percentage/number than ONA for the glabellar and crow's feet regions, although there was an increase in the number of patients who reported no difference between the two treatments at this time. Response rates for $\mathrm{ABO}$ and $\mathrm{ONA}$ were equivalent in both regions up to approximately 3 months; however, the response rates were higher at 4 and 5 months with ABO. Patient satisfaction findings were generally consistent with evaluator assessments at each time point.

Rapid onset was observed with ONA in a short-term 14-day study [16]. Beer et al. evaluated the onset of action of ONA and found that $48 \%$ of patients reported improvement by day $1,77 \%$ by day $2,93 \%$ by day $3,98 \%$ by day 4 , and $100 \%$ thereafter. In the current study, $\mathrm{ABO}$ and ONA were administered in the glabellar region at a ratio of 2.5:1 (20 U for $A B O$ vs $8 U$ for ONA) and in the crow's feet region at a ratio of 3:1 (30 U for $\mathrm{ABO}$ vs $10 \mathrm{U}$ for ONA). Three studies by Lowe et al. compared the efficacy of ABO and ONA for upper facial lines. In one study, injecting glabellar lines at doses of ONA (30 U) and ABO (75 U; 2.5:1 ratio) showed similar efficacy. In another study, ONA (256 U total) was significantly more effective than $\mathrm{ABO}$ (64 U total) (dose ratio of $4: 1$ ) for upper face lines. However, an objective measurement by computerized photographic numerical assessment showed greater efficacy in the crow's feet region with $A B O$ vs ONA when a 3:1 dose ratio (96 U:32 U) was used [17].

Both $\mathrm{ABO}$ and ONA have the same pharmacology and act by inhibiting the calcium-mediated release of acetylcholine from the nerve ending, causing temporary muscle paralysis. Side effects can occur and range from mild due to the injection itself or severe due to the effects of the toxin such as difficulty swallowing, difficulty breathing, double or blurred vision, change of voice, or muscle weakness. The safety profile was similar for both products with mild adverse events reported, which resolved within one week. One (of 85) patients developed brow ptosis on the side that was injected with $\mathrm{ABO}$. Brow ptosis is said to develop by diffusion of the toxin into the frontalis from the corrugator muscle. More dilute concentration is preferable in order to increase spread and field of effect (as in the forehead), whereas lower volumes are preferred in smaller muscle groups to avoid migration into unplanned areas [18]. On the other hand, more concentrated solutions reduce reliability in delivering a specific unit dose, and more dilute solutions lead to greater spread of the toxin [18]. In our study, ABO was given as a dilution of $300 \mathrm{U}$ in $3 \mathrm{ml}$ for the glabellar and crow's feet areas and ONA was reconstituted with $2.5 \mathrm{ml}$ in a $100 \mathrm{U}$ vial for the glabellar area and $3 \mathrm{ml}$ for the crow's feet area. For the glabellar region, we recommend adjusting the amount of diluent $(1.5-2.5 \mathrm{ml})$ for both $\mathrm{ABO}$ and ONA to result in a more concentrated solution in order to decrease the migration of treatment into the levator and frontalis muscle and prevent brow ptosis. 
In our study, we sought to achieve the minimal efficacious dose that would produce optimal benefits with the lowest risk. At doses of 20 and $30 \mathrm{U}$ ABO for the unilateral glabellar and unilateral crow's feet regions, respectively, onset of action based on patient selfassessment was shown to be significantly quicker than with ONA at $8 \mathrm{U}$ in the unilateral glabellar and $10 \mathrm{U}$ in the crow's feet regions. Other studies compared the efficacies of $\mathrm{ABO}$ and ONA in different patients and thus do not account for variations between individuals, such as muscle mass and severity of wrinkles [17]. The current study was an internally controlled, prospective study with blinding of the patients as well as the evaluators and thus established better measures to compare clinical efficacy (Fig. 7).

We used three injections for the corrugator unilaterally although in clinical practice, two injections are used for this muscle. The dose of $\mathrm{ABO}$ recommended by the label (50 $\mathrm{U}$ for the frown on both sides, $10 \mathrm{U}$ per injection point, 5 injection points) gives $20 \mathrm{U}$ for each corrugator, which is the same dose used in our study. We

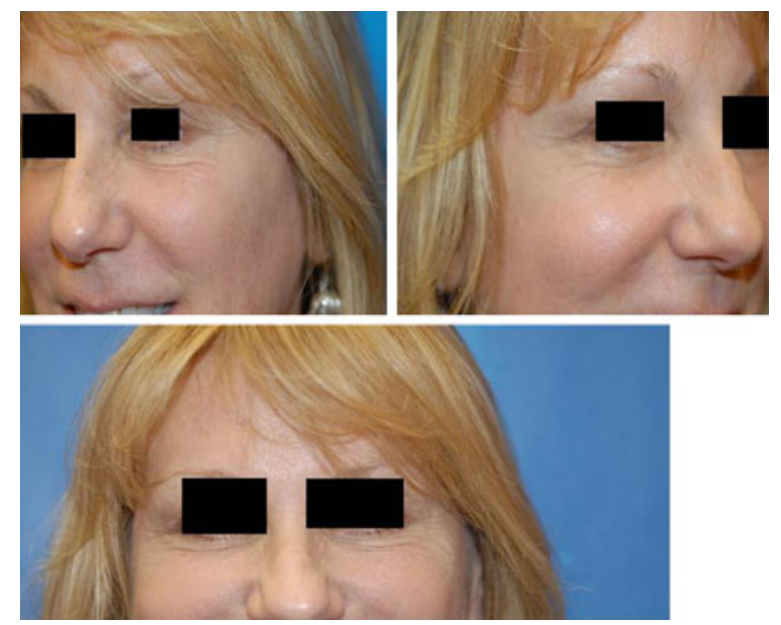

Fig. 7 a Patient with ONA injected into the right crow's feet ( 3 months). b Patient with $\mathrm{ABO}$ injected into the left crow's feet ( 3 months). $\mathrm{ABO}$ is more effective at 3 months than ONA spread the dose over three points instead of two for the purpose of better anatomic treatment of the corrugator and to have the patient serve as their own internal control in order to objectively measure the differences in efficacy between the two treatments. The findings from our study, which establishes key parameters (onset of action, duration of effect, doses, and side effects) for $\mathrm{ABO}$ and ONA, allows the patient to opt for the more beneficial and economic product with little risk of adverse effects, a desirable faster onset with a longer duration between treatments.

The major limitation of the study was that we could not inject the glabellar muscle as is done in practice in order to make comparisons between the two treatments in the frown region.

\section{CONCLUSION}

In conclusion, our experience with $\mathrm{ABO}$ demonstrated a greater duration of activity and more rapid time to onset in a larger number of patients in comparison with ONA when used at a dose ratio of 2.5:1 in the glabellar region and 3:1 in the crow's feet region. The safety profile was similar for both products. These findings suggest that $\mathrm{ABO}$ is a safe effective alternative to ONA when injected for treatment of wrinkles in the glabellar and crow's feet areas. For the glabellar area, we recommend more concentrated forms, more injection areas, and more superficial injections to decrease the incidence of brow or eyelid ptosis and to decrease the migration of treatment.

\section{ACKNOWLEDGMENTS}

Sponsorship for this study was funded by Mona Lisa Cosmetic Surgery Center. This study was 
not sponsored by Medicis or Allergan. Dr Ramtin Kassir is the guarantor for this article, and takes responsibility for the integrity of the work as a whole.

Conflict of interest. Dr Ramtin Kassir is a national trainer for Medicis. Dr Aparanjita Kolluru and Dr Martin Kassir declare no conflicts of interest.

Compliance with ethics guidelines. All procedures followed were in accordance with the ethical standards of the responsible committee on human experimentation (institutional and national) and with the Helsinki Declaration of 1975, as revised in 2000 and 2008. Informed consent was obtained from all patients for being included in the study. Additional informed consent was obtained from all patients for which identifying information is included in this article.

Open Access. This article is distributed under the terms of the Creative Commons Attribution Noncommercial License which permits any noncommercial use, distribution, and reproduction in any medium, provided the original author(s) and the source are credited.

\section{REFERENCES}

1. Frampton JE, Easthope SE. Botulinum toxin A (Botox cosmetic): a review of its use in the treatment of glabellar frown lines. Am J Clin Dermatol. 2003;4: 709-25.

2. Matarasso S, Matarasso A. "M" marks the spot: update on treatment guidelines for botulinum toxin type A for the periocular area. Plast Reconstr Surg. 2003;112:1470-2.

3. Farahvash MR, Arad S. Clostridium botulinum type A toxin for the treatment of upper face animation lines: an Iranian experience. J Cosmet Dermatol. 2007;6:152-8.
4. Lietzow MA, Gielow ET, Le D, Zhang J, Verhagen MF. Subunit stoichiometry of the Clostridium botulinum type A neurotoxin complex determined using denaturing capillary electrophoresis. Protein J. 2008;27:420-5.

5. Pickett A, Caird D. Comparison of type a botulinum toxin products in clinical use. J Clin Pharm Ther. 2008;33:327-8.

6. Beylot C. Different botulinum toxins and their specifications. Ann Dermatol Venereol. 2009; 136(Suppl 4):S77-85.

7. Brauser D. ASDS 2008: Clostridium Botulinum type A toxin appears fast acting, long lasting in treating glabellar lines. Available at http://www.medscape. com/viewarticle/583478. Accessed March 10, 2010.

8. Ascher B, Rzany B, Grover R. Efficacy and safety of botulinum toxin type $A$ in the treatment of lateral crow's feet: double-blind, placebo-controlled doseranging study. Dermatol Surg. 2009;35:1478-86.

9. Barclay L. New botulinum toxin may be effective, well tolerated for wrinkles. Available at http://www. medscape.com/viewarticle/589721. Accessed October $16,2010$.

10. Lowe P, Patnaik R, Lowe N. Comparison of two formulations of botulinum toxin type A for the treatment of glabellar lines: a double-blind, randomized study. J Am Acad Dermatol. 2006;55: 975-80.

11. Matarasso A, Chia C, Plastic Surgery Educational Foundation DATA Committee. Follow-up: botulinum toxin. Plast Reconstr Surg. 2003;112(5 Suppl):62S-5S.

12. Rubin M, Dover JS, Glogau RG, et al. The Efficacy and safety of a new U.S. botulinum toxin type A in the retreatment of glabellar lines following open-label treatment. J Drugs Dermatol. 2009;8(5):439-44. Available at http://findarticles.com/p/articles/mi m0PDG/is_5_8/ai_n32147651/. Accessed October $18,2010$.

13. First-ever standardized scales to measure the skin's aging process are introduced at The American Society For Plastic Surgery's Annual Meeting. 5 May 2009. Available at: http://www.medicalnewstoday. com/articles/148766.php. Accessed March 8, 2010 .

14. Honeck P, Weiss C, Sterry W, Rzany B. Reproducibility of a four-point clinical severity score for glabellar frown lines. $\mathrm{Br} \mathrm{J}$ Dermatol. 2003;149:306-10.

15. Hund T, Ascher B, Rzany B. Reproducibility of two four-point clinical severity scores for lateral 
canthal lines (crow's feet). Dermatol Surg. 2006;32: 1256-60.

16. Beer KR, Boyd C, Patel R, et al. Rapid Onset of response and patient-reported outcomes after onabotulinumtoxinA treatment of moderate-tosevere glabellar lines. J Drugs Dermatol. 2011;10: 39-44.
17. Lowe NJ, Shah A, Lowe PL, Patnaik R. Dosing, efficacy and safety plus the use of computerized photography for botulinum toxins type A for upper facial lines. J Cosmet Laser Ther. 2010;12:106-11.

18. Hauser RA, Wahba M, McClain T. BOTOX injections. Available at http://emedicine.medscape.com/article/ 1271380-overview. Accessed January 23, 2011. 